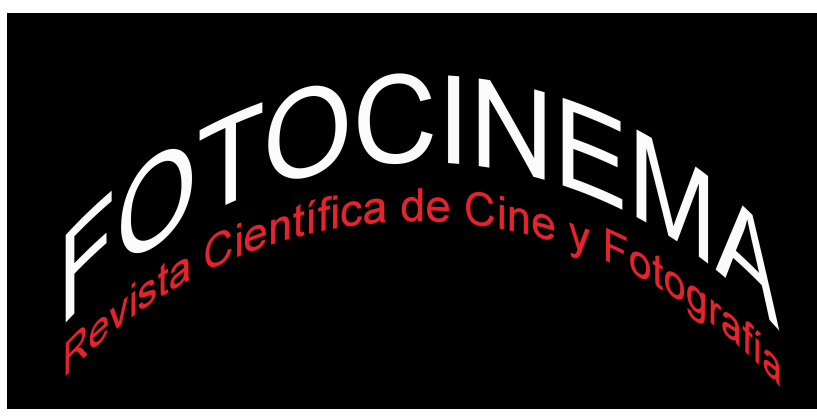

\title{
FRENÉTICO, EL ESPACIO-TIEMPO EN LA FOTOGRAFÍA ARTÍSTICA CONTEMPORÁNEA
}

\section{FRENETIC, THE SPACE-TIME AT THE ARTISTIC CONTEMPORARY PHOTOGRAPHY}

\author{
Gema Pastor Andrés \\ Universidad Rey Juan Carlos, Madrid, España \\ gema.pastor@urjc.es
}

\section{Resumen:}

Este texto estudia las nuevas ideas de la física representadas en el arte.

Einstein revolucionó las ciencias a principios del siglo XX; y hoy sus ideas sobre el espacio-tiempo se han asentado y confirmado en el día a día.

Las relaciones entre el entorno urbano y global con sus habitantes responden a esas nuevas formas de entender el espacio-tiempo.

El estado natural de todo cuerpo es el movimiento y en el espacio-tiempo curvo en el que nos encontramos no pueden separarse el marco de las figuras. Para esas ideas la fotografía artística contemporánea propone novedosas maneras de dibujar la imagen fotográfica: fórmulas alejadas de la óptica cónica, el ojo único, la vista completa enfocada... sin dejar de responder a la figuración y la toma directa. Fórmulas que representan las relaciones y sensaciones de los habitantes del entorno actual.

\begin{abstract}
:
This essay reflects on the new ideas of physics that are represented in art.

Einstein shook up Science in the early Twentieth century; nowadays, his ideas about space-time have settled and are confirmed on a daily basis.

The relationship between the urban setting and its inhabitants respond to those new forms of understanding space-time.

The natural condition of all bodies is that of movement, and in the curved space-time we live in it is not possible to separate the frame from the figures. In relation to those ideas, contemporary artistic photography proposes new ways of depicting a photographic image: methods that are far apart from a conic projection from camera lens, the singular point of view, everything under focus... without moving away from the figurative image and the direct shoot. These formulas represent relations and perceptions of the inhabitants of our present environment.
\end{abstract}

\section{Palabras clave:}

Espacio-tiempo; paisaje; fotografía; movimiento; dinámico; entorno urbano.

\section{Keywords:}

Space-time; Landscape; Photography; Movement; Dynamic; Urban Envoiremen. 


\section{Introducción}

El texto que sigue propone una contemplación detenida sobre algunas fotografías del entorno urbano actual que miran el tiempo-espacio de nuestros días revelando cómo es y cuál es la relación con las personas que lo viven.

La comprensión del espacio-tiempo en la actualidad ya no se reconoce con la contigüidad lineal del Renacimiento. Los cambios en la interacción con él, que comenzarón al principio del siglo $\mathrm{XX}$, producen nuevas maneras de comprenderlo y asimilarlo:

Es notable la conjunción de todos estos nuevos enfoques en la filosofía de la conciencia del tiempo, la física, las matemáticas, la pintura, la arquitectura, la música, la novela y la historiografía en esta década de 1905-1915. Hubo factores internos en cada disciplina o arte que explicaran su transformación, independientemente de si se habían influido unas a otras. Pero lo importante es que todas ellas rechazaron la perspectiva lineal de la visualidad y la razón arquimédica, en aquel decenio crucial de 1905-1915. Desde luego, aún en la actualidad algunas personas siguen trabajando con las viejas presuposiciones. Pero el nuevo enfoque multiperspectivo expresa una sensibilidad enteramente distinta; pues el espacio y el tiempo ya no pueden, en el siglo XX, ser el marco objetivo e indudable de la percepción, sino que se han convertido, a su vez, en aspectos de un sistema funcional, y cambian junto con él (Lowe, 1986, p. 7).

La transformación de las artes dio lugar al desarrollo de las vanguardias, cubismo, futurismo... con sus nuevas formas de mirar, pensar y representar el mundo, que marcarón los caminos posibles para el arte del futuro. Desde entonces el mundo no sólo se puede pensar desde estos parametros sino que se construye a partir de ellos, al observar lo que nos rodea podemos tener una sensación múltiple, variada y en movimiento.

La ciudad proporciona estas sensaciones no en nuestra mirada directa sobre ella, sino en la interiorización de la misma, no tanto en cómo se ve, sino en cómo se siente. Según las propias palabras del fotógrafo italiano Davide Bramante, su obra revela una interiorización del entorno. La manera en que fotografio es igual al modo en que recuerdo, pienso, sueño, deseo, todo 
ocurre por la superposición temporal y espacial (Bramante, s.f.). Las imágenes de la serie My Own Rave, a la que ha dedicado toda su trayectoria, son fotomontajes de distintas vistas sobre un mismo lugar o sobre distintos enclaves siempre fijando su atención en la ciudad. Las imágenes planas funcionan como un reflejo transparente que permite una visión múltiple.

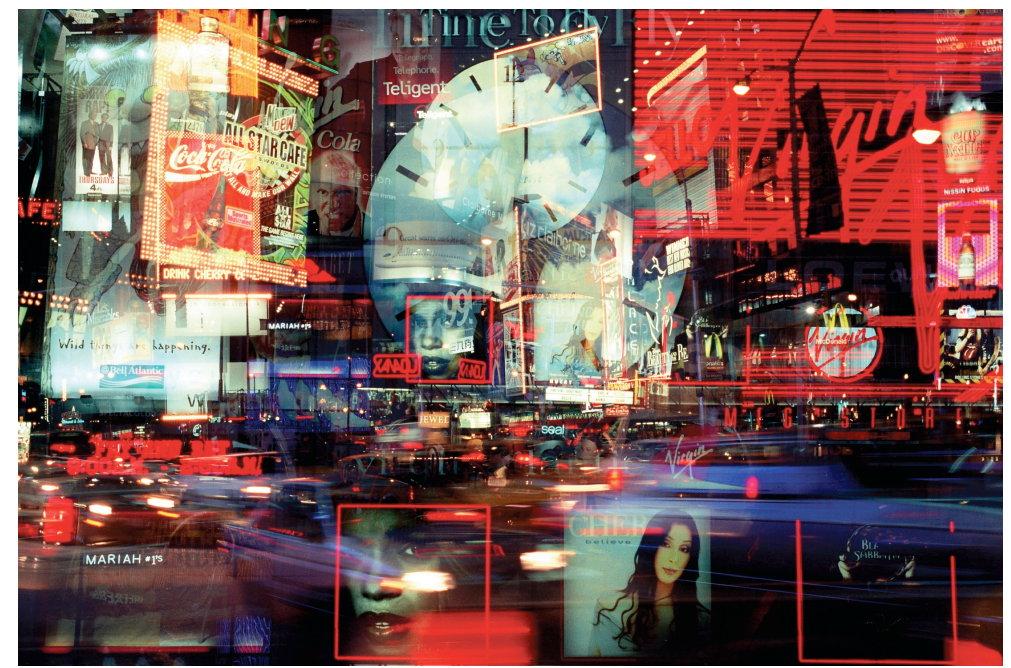

F1. Time Square, 1998, de la serie My Own Rave de Davide Bramante

En una de las primeras fotografías de su serie My Own Rave, Time Square 1998, la recreación de las sensaciones del entorno contemporáneo se produce a partir de la mezcla en una sola imagen de distintos puntos de vista de este centro comercial y de negocios de la ciudad de Nueva York, se repiten partes situadas en distintas posiciones del cuadro, con diferentes tamaños y perspectivas con respecto al resto. Una sola imagen suma diferentes ángulos de visión, encuadres, obturaciones, tomas, desde aquí y desde allí (de cerca o de lejos, arriba o abajo, más a la derecha o a la izquierda).

La superposición de estos puntos de vista, ráfagas y barridos devuelve una imagen única y a la vez múltiple del entorno: pantallas inmensas, luminosos, ráfagas desde el transporte, publicidad, vallas, señales, etc.; miles de mensajes en un entorno saturado y rápido.

Cada artista refleja en su obra la visión, no sólo del mundo que le rodea, que también, sino la forma de ver y de pensar del momento en el que vive, a través de la lectura de las imágenes que generan podemos apreciar: ċuál es 
el imaginario colectivo que sustenta el paisaje civilizado que vivimos?, ¿cómo es el paisaje actual?, ¿qué sentimientos y sensaciones nos quieren transmitir?, ¿qué podemos sentir y hacer ante sus obras... y ante el mundo que vivimos a través de su mirada?

La investigación realiza, a partir del análisis de varias obras contemporáneas, un acercamiento a las nuevas formas de pensar y entender el tiempo y el espacio de nuestros días. Primero se recopilan las ideas sobre el espaciotiempo que las ciencias puras llevan defendiendo en el último siglo, sirven para elegir las imágenes y descubrir cómo esos paradigmas son plasmados por el arte (Kuhn, 1962). Después se dibuja una metodología, utilizando como base una definición propia de paisaje, que se volcará sobre las imágenes seleccionadas para descubrir las formas del paisaje contemporáneo y de representación qué nos proponen las obras.

\section{Marco teórico y metodología}

\subsection{Espacio-tiempo, el marco teórico}

Espacio. (Del lat. spatǐum). 1. m. Extensión que contiene toda la materia existente. 2. m. Parte que ocupa cada objeto sensible. 3. m. Espacio exterior. 4. m. Capacidad de terreno, sitio o lugar. 5. m. Transcurso de tiempo entre dos sucesos. 6. m. Tardanza, lentitud. 7. m. Distancia entre dos cuerpos (RAE, Real Academia Española).

Las primeras acepciones de la Real Academia hacen referencia a la esencia del espacio estudiada por la física y que tienen influencia epistemológica sobre todas las ciencias. La manera de concebir el espacio ha evolucionado a lo largo de la historia y estas distintas formas de entenderlo reflejan cómo se comprende y percibe en cada momento (Kuhn, 1962). El espacio cognitivo de la física delimita los dominios conceptuales a través de los cuales se piensa la materia y su entorno. ¿Cómo se concibe el espacio en la actualidad?

La concepción del espacio actualmente está determinada por las ideas definidas en el siglo XVII por Isaac Newton, y la revisión de las mismas que a 
comienzos del siglo XX realizó Albert Einstein. El universo, desde Aristóteles y Euclides hasta Galileo y Newton, se concebía de manera estática, se creía que el estado natural de un cuerpo era el reposo. Sin embargo, el espaciotiempo de nuestros días ya no es el marco fijo que no se ve influido por lo que sucede en él (Lowe, 1986).

Las Leyes del Movimiento y la Ley de Gravitación Universal de Newton terminaron con el concepto de una posición fija en el espacio, y la Teoría de la Relatividad (Especial y General) de Einstein acabó con la idea de un tiempo lineal continuo e independiente del espacio, y definió la relación entre los sucesos y el entorno. La física se ha ocupado y sigue ocupandose de entender el estado de todo cuerpo (del reposo al movimiento), y la relación entre ellos y la forma del espacio (de la gravedad al espacio curvo). En la actualidad, nuestro modelo de espacio y de tiempo sigue estando basado en las propuestas de Einstein (Hawking, 2002, p. 34).

\subsubsection{Movimiento}

En 1687 Newton publicó el libro más influyente de la historia de la física: Philosophiae Naturalis Principia Mathematica (Principios Matemáticos de la Filosofía Natural). En él expone su modelo matemático del tiempo y del espacio, demuestra que no existe un estándar de reposo (Leyes del movimiento), y explica la atracción que los cuerpos ejercen unos sobre otros en función de su masa (Ley de Gravitación Universal). Siempre que sobre un cuerpo no actuara ninguna fuerza, éste se mantendría moviéndose en una línea recta con la misma velocidad (Hawking, 1990, p. 36).

Pero Newton, al igual que Aristóteles, seguía pensando que el tiempo y el espacio eran independientes. En el modelo de Newton, el tiempo y el espacio constituían un fondo sobre el cual se producían los sucesos, pero que no era afectado por ellos. El tiempo estaba separado del espacio y era considerado como una línea infinita en ambas direcciones. A comienzos del siglo XX, con la Teoría de la Relatividad Especial, Einstein demuestra que no existe un tiempo absoluto, puesto que las leyes (de la física) deben de ser iguales para 
todos los observadores y esto no ocurre con las afirmaciones de Newton. ¿Qué ocurriría si dos espectadores, uno dentro de un tren y otro fuera, que observan el mismo suceso sacaran diferentes conclusiones?

Por ejemplo, al jugar al ping-pong en el tren, uno encontraría que la pelota obedece las leyes de Newton exactamente igual a como lo haría en una mesa situada junto a la vía. Por lo tanto, no hay forma de distinguir si es el tren o es la tierra lo que se mueve. (...) Supongamos que en el tren nuestra bola de pingpong está botando, moviéndose verticalmente hacia arriba y hacia abajo y golpeando la mesa dos veces en el mismo lugar con un intervalo de un segundo. Para un observador situado junto a la vía, los dos botes parecerán tener lugar con una separación de unos cuarenta metros, ya que el tren habrá recorrido esa distancia entre los dos botes. Así pues la no existencia de un reposo absoluto significa que no se puede asociar una posición absoluta en el espacio con un suceso, como Aristóteles había creído. Las posiciones de los sucesos y la distancia entre ellos serán diferentes para una persona en el tren y para otra que esté al lado de la vía, y no existe razón para preferir el punto de vista de una persona frente al de la otra (Hawking, 1990, p. 39).

Por lo tanto, un suceso es aquello que ocurre en un punto del espacio en un instante del tiempo, sin que estas dos dimensiones puedan separarse. Los sucesos ocurren en un espacio-tiempo cuatridimensional ( $\mathrm{x}, \mathrm{y}, \mathrm{z}, \mathrm{t})$, por lo que no existe diferencia entre cualquiera de las dimensiones espaciales y la temporal.

La teoría de la relatividad nos fuerza, a cambiar nuestros conceptos de espacio y tiempo. Debemos aceptar que el tiempo no está completamente separado e independiente del espacio, sino que por el contrario se combina con él para formar un objeto llamado espacio-tiempo (Hawking, 1990, p. 47).

\subsubsection{Universo dinámico}

Con la Ley de Gravitación Universal Newton había descubierto que cada cuerpo atrae a todos los demás con una fuerza proporcional a su masa y que esta atracción está también en relación con la distancia que exista entre ellos. 
Años más tarde, en 1915, Einstein desmontaría esta teoría revolucionando la física con la Teoría de la Relatividad General.

La gravedad no es una fuerza como las otras, sino que es una consecuencia de que el espacio-tiempo no sea plano (...) está curvado, o "deformado", por la distribución de la masa y energía en él presente (Hawking, 1990, p. 57).

La consecuencia de esta teoría es que la concepción del espacio deja de ser la de un plano infinito para convertirse en un espacio-tiempo curvo donde todo está interrelacionado. El espacio y el tiempo son cantidades dinámicas, lo que ocurre les altera y su estructura curvada influye en cómo pasan las cosas. Cuando un cuerpo se mueve, o una fuerza actúa, la curvatura del espacio y del tiempo se ve afectada, y de igual manera, la estructura del espacio-tiempo dispone el modo en que los cuerpos se mueven y las fuerzas actúan.

La concepción física del espacio-tiempo de nuestros días dibuja un entorno dinámico, y de cuatro dimensiones, donde los distintos actores y el escenario no se pueden separar. El entorno espacio-tiempo no es fijo y depende de las interacciones de las fuerzas, de las masas, y de su propia estructura. Esta concepción del entorno establece una situación en el mismo ligada al movimiento provocado por la continua interacción de fuerzas, masas y entornos espacio-temporales. Estas teorías, aparentemente incomprensibles para el individuo en la actualidad, han sido asimiladas y se han materializado en la sociedad contemporánea.

El mundo ha cambiado mucho más en los últimos cien años que en cualquier siglo precedente. La razón de ello no han sido las nuevas doctrinas políticas o económicas, sino los grandes desarrollos auspiciados por los progresos en las ciencias básicas (Hawking 2002, p. 26).

La percepción del mundo en la actualidad responde a estas premisas. El individuo actual se encuentra en continuo movimiento en el espacio-tiempo dinámico. La masa, la fuerza y la forma curvada del espacio-tiempo están en relación: ¿tiene esto consecuencias tangibles en nuestro mundo?, ¿cómo es la atracción que ejercen algunas ciudades sobre el resto del entorno?, ¿cómo se produce el continuo, acelerado e incesante movimiento en el que vivimos? El 
individuo de nuestros días está situado en la totalidad del mundo porque lo concibe como un conjunto abarcable mental y literalmente (físicamente).

\subsection{Paisaje}

Para sentir el entorno el ser humano ha inventado el paisaje. La idea es relativamente nueva (200 d.C. en China y en el siglo XV en Europa, a pesar de que hacía 1500 Durero ya pinta unos magnificos bocetos del paisaje), y nace cuando el ser humano es capaz de idealizar su entorno más allá de su utilización o provecho (Maderuelo 1996). La idea de paisaje está ligada a los dos elementos indispensables para su gestación: el individuo mirando y el entorno mirado, el paisaje no existe sin una perspectiva humana sobre el mismo (Kessler, 2000, p. 9).

El paisaje no es el entorno, es una visión particular sobre él, cuando el ser humano aprecia el entorno por la vista, lo que hace es crear paisaje, la idea es indisoluble de la presencia en el entorno del ser que lo observa. La relación establecida entre el observador y el entorno observado da como fruto un sentimiento sobre el mismo (además de establecer un orden visual). Desde que es descubierta, esta manera de relacionarse con el entorno cambiará para siempre la relación entre ambos (Calvo, 2005). La mirada, la interiorización del entorno por el ser humano, produce sensaciones, y de estas sensaciones surge la necesidad de representación del entorno. Tanto es así que su definición sirve tanto para explicar la observación directa del paisaje como su representación.

El paisaje es lo que podemos ver -apreciar- en la distancia, tanto el horizonte como el cuadro. El paisaje es el paradigma de la distancia a través de la visión. Tanto el entorno observado como el representado sólo pueden ser apreciados a través del sentido de la visión. Además, ambos, la vista y la representación, son producto de una visión personal, reflejan el entorno interiorizado. 
La visión del observador, o del artista, refleja los sentimientos que la observación provoca, y son los artistas los que nos permiten apreciar esas sensaciones irradiadas en sus obras (Gombrich, 2002).

\subsubsection{Metodología}

Esta definición de paisaje nos sirve para obtener las sustancias que escudriñar en las fotografías, unas serán los significantes (las formas), otras los significados (el fondo), que construyan la obra de arte completa; dibujando la metodología a aplicar en la lectura de estas obras de la fotografía artística contemporánea.

La fotografía de paisaje es sensible por la distancia que propone en la representación y en el horizonte, a través del sentido de la vista. Estos elementos son los significantes (la forma) de la imagen, diseñan la representación y permiten su visión. Entendemos la fotografía como imagen plana que plasma una representación figurativa, y a partir de esa premisa estudiaremos cuáles son las convenciones formales y culturales de la imagen que sostienen o rompen las fotografías contemporáneas de paisaje, es decir, sus significantes, cómo está representado.

La fotografía de paisaje es sensible en lo que significa (en el fondo, en lo que quiere contar) porque es reflejo del entorno interiorizado y provoca sensaciones. Estos elementos se refieren a los significados de la imagen. Para su estudio proponemos descomponerlo en tres sustancias: contexto, acción y reacción (el primero de ellos podría concebirse como el fondo y los otros dos como las figuras dentro y fuera del cuadro).

La fotografía es un medio que siempre ha estado asociado de un modo u otro a la construcción de una mirada sobre el mundo. Cuando esa construcción se configura con rotundidad conlleva además el desarrollo de una experiencia sobre los lugares y las personas (Martín, 2007).

La primera de las sustancias se refiere al contexto representado, ¿qué es lo que hay representado? La mirada sobre el mundo deviene de la experiencia 
sobre el entorno, y ese entorno es el que queda representado en las fotografías. Ese contexto representado puede interiorizarse y provocar sensaciones. La segunda y la tercera de las sustancias son las que construyen las personas a partir de las fotografías.

Para mí existían - de ello me doy cuenta retrospectivamente - dos campos, dos lados en fotografía. En uno estaba el acontecimiento y la acción, en el otro, el paisaje, la contemplación. El pasaje de un lado a otro se hacía a través de la memoria. Una imagen de reportaje fija un acontecimiento para la memoria futura. El fotógrafo trabaja en el futuro anterior (esto habrá sido). En el lado del paisaje, la memoria produce más bien un efecto de alejamiento. La actualidad de la vista es tomada en una duración que sobrepasa la biografía consciente del fotógrafo (Chevrier, 2007, p. 11).

Estos dos lados de la fotografía, que explica Chevrier, responden a las dos sustancias indisolubles que la construyen a través de la memoria, es la relación que surge entre las personas y la imagen. Por un lado, el reflejo del entorno interiorizado por el artista que propone con su obra una acción. El artista construye la memoria para la futura acción, ¿cuál es la acción que propone el artista? (Chevrier lo llama el acontecimiento, la acción). Por otro lado, la fotografía provoca sensaciones en el espectador que sobrepasan las intenciones del fotógrafo. Es la reacción del que reconstruye su memoria a través de la fotografía, ¿cuál es la reacción que provoca la imagen en el espectador? (Chevrier lo llama la contemplación).

Como forma codificada culturalmente la foto documental, en cualquiera de sus variantes, incluida la fotoperiodismo, la foto no-evenemencial o la ficción documentada, incluye el contexto e incluye el receptor como imprescindibles para la significación. La palabra foto, una de las muchas posibilidades de la imagen, continúa remitiéndonos a la alteridad, a la idea del otro y nos permite, de nuevo, su abordaje desde la teoría para hacer visibles los modos de reivindicar la realidad, la realidad como el lugar en el que se materializa la experiencia, personal y social, y donde, cada vez más, las propuestas vuelven a ser explicitas. La palabra foto, nos reclama, al mismo tiempo, relacionarnos con la diversidad como territorio autoral (Ledo, 1998, p. 149). 
El análisis que continua se estructura, a partir de estos conceptos nacidos del paisaje, como un boceto en el que volcar las imágenes con la siguente estructura. Primero justificamos la elección de las fotografías para tratar el tema que nos ocupa, el espacio-tiempo, a través de su descripción literal, de lo que dicen los autores de ellas o del título. Después estudiamos el significado del título de la fotografía y su relación con la imagen. Luego describimos los significantes de la imagen: cómo es representado el entorno en la fotografía, la estética de las imágenes, los elementos como imagen plana bidimensional, perspectivas, líneas, color... y los referentes icnográficos, plásticos, estéticos... Por último descubrimos los significados en tres sustancias: contexto (qué es lo que está plasmado), acción (propuesta por el fotógrafo) y reacción (qué provoca en el espectador). Todo esto revelará cuáles son los paradigmas y los imaginarios que sustentan las relaciones del espacio-tiempo con sus habitantes plasmados por estos artistas.

Si lo denominamos boceto es porque no supone un esquema cerrado a partir del que se rellenan los contenidos, sino que es abierto y los distintos apartados se complementan unos a otros. Al igual que la fotografía muestra todas sus partes de una vez, su análisis no puede separarlas si no es para relacionar unas con otras, pues la fotografía se compone de todas ellas en su conjunto.

\section{Fotografía artística}

\subsection{Múltiple}

Fijémonos en la foto de Michael Najjar México (F2), de la serie de Netropolis realizada entre 2003 y 2006. La imagen en blanco y negro nos muestra superpuestas las vistas aéreas de México obtenidas a través de una exposición múltiple. 


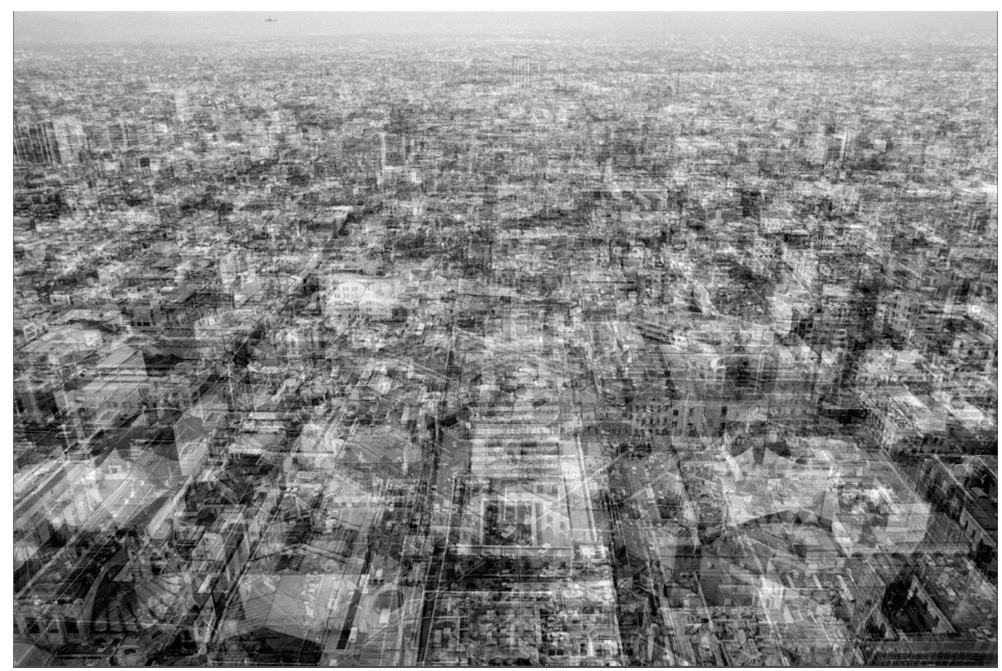

F2. México, de la serie Netropolis, 2003-2006, de Michael Najjar

Vista desde el cielo vemos la conurbación urbana más poblada de todo el continente americano con unos 20 millones de habitantes en el año 2010; sólo México DF tiene 8 millones en una superficie de 1400 kilómetros cuadrados. La fusión de las distintas vistas aéreas en la que se mezclan los rascacielos convierte la superficie de la fotografía en una isometría de malla tridimensional en la que se entrecruzan líneas verticales y horizontales proyectadas a distintos niveles. La imagen pertenece a la serie más conocida del artista alemán, Netropolis, donde recopila la visión aero-poliédrica y reticular de las ciudades más grandes del mundo revelando los umbrales posibles para su concepción.

Como obra del arte visual, la Netropolis elude los marcos de nuestra experiencia visual. Vista de cerca, sólo muestra secciones y segmentos; vista de lejos, todos los detalles se pierden. Como un complejo objeto de múltiples capas de redes, la ciudad sólo puede entenderse en términos de experiencia real como una sección. La ciudad de Sao Paulo, por ejemplo, abarca una superficie total de 1.500 kilómetros cuadrados. Cualquier intento de comprender esta inmensidad como una totalidad unificada está condenado al fracaso. La ciudad como una construcción artificial, sólo puede ser experimentada en términos de la interacción dialéctica entre el microcosmos y macrocosmos, entre la realidad y la simulación (Najjar, 2004). 


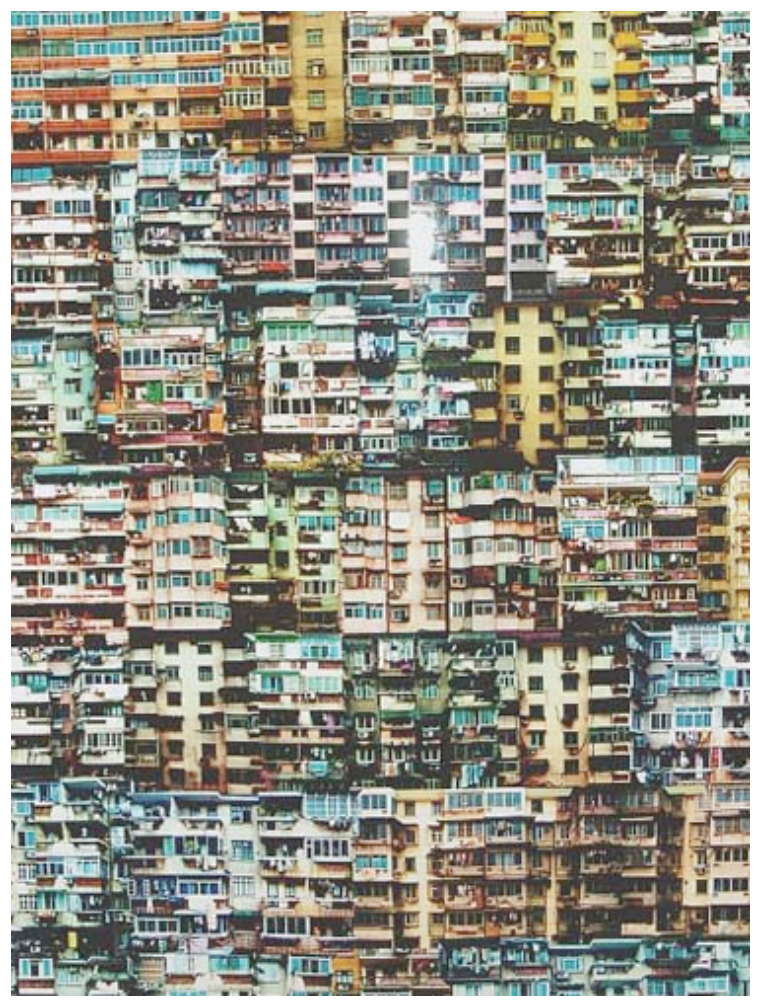

F3. De la serie Rock Never, 2002, de Xiang Liqing

El artista Xiang Liqing retrata en uno de los montajes de su serie Rock Never de 2002 (F3) las fachadas de los bloques de pisos de la zona del delta del río de la Perla en el sudeste de China, donde vive. El collage, con las fachadas repetidas de forma sistemática una tras otra, simula una gran colmena. La duplicación cuadriculada de los edificios de nueva construcción amplifica la visión de una arquitectura uniforme. Pero si miramos de cerca la imagen descubriremos que los fragmentos que la componen son distintos, la fuerza de este trabajo se basa en su ambivalencia, cuando uno examina cada minúsculo balcón, se ve cómo cada persona ha alterado el espacio en el que él o ella vive. La imagen dis-tópica de la vivienda pública se transforma.

Con su intensa atención a los detalles: las diversas formas de ventanas, la ropa que cuelgan a secar, una planta que goza la luz del sol; Xiang crea un sentido de espacio personal, que contrasta marcadamente con sus rascacielos. En lugar de cancelar la posibilidad de la expresión individual, la arquitectura de la existencia urbana es transformada por los que la utilizan. De esta manera, los edificios de Xiang evocan una especie de gabinete de curiosidades: como una 
bodega donde vemos vastas colecciones de individuos, cuyo principio unificador es la fuerza de sus diferencias (Spalding, 2003).

Ambas imágenes son distintas vistas de cerca o vistas de lejos, una profundidad que nos permitiese verlo todo desde distintas distancias es imposible. Si nos aproximamos sólo veremos partes y segmentos, si nos alejamos todos los detalles se pierden y la imagen devuelve una imbricada red donde se repiten de forma sistemática estructuras similares.

La composición digital que las ha generado no facilita la percepción de estas dos dimensiones en un solo vistazo. Las imágenes están compuestas de tal manera que su visión responde a la misma sensación que genera el entorno. Conocemos las dos dimensiones que lo componen, de cerca y de lejos, pero somos incapaces de apreciar ambas al tiempo. Parece que estamos delante de una imagen ambigua o una ilusión óptica, como si miráramos las caras/vaso de Rubin, sólo podemos ver los detalles de cerca o la malla repetitiva de lejos, alternativamente la una o la otra dependiendo de dónde fijemos nuestra atención, el ojo ve las dos, pero el cerebro, que ordena la información proporcionada por la vista en función de los esquemas perceptivos lee una o la otra según el esquema que apliquemos.

$\mathrm{Al}$ igual que en el dibujo de Rubin, en la ciudad no podemos ver ambas cosas a la vez, aunque somos capaces de comprender que forman parte de un todo, no lo podemos ver aunque lo podemos concebir, como la interacción dialéctica entre el microcosmos y el macrocosmos (Najjar, 2004).

\subsection{Rápido}

La gestación de este modelo de organización territorial es fruto de un intenso desarrollo de los medios de transporte que propició que cambiara de forma radical la percepción del tiempo y del espacio. Con el paso de los años, el cerebro humano se fue acostumbrando a la visión difuminada del paisaje que se tiene a través de la ventanilla de un tren o de un automóvil en marcha y, a día de hoy, la velocidad se ha convertido en algo rutinario (Vega, 2007). 


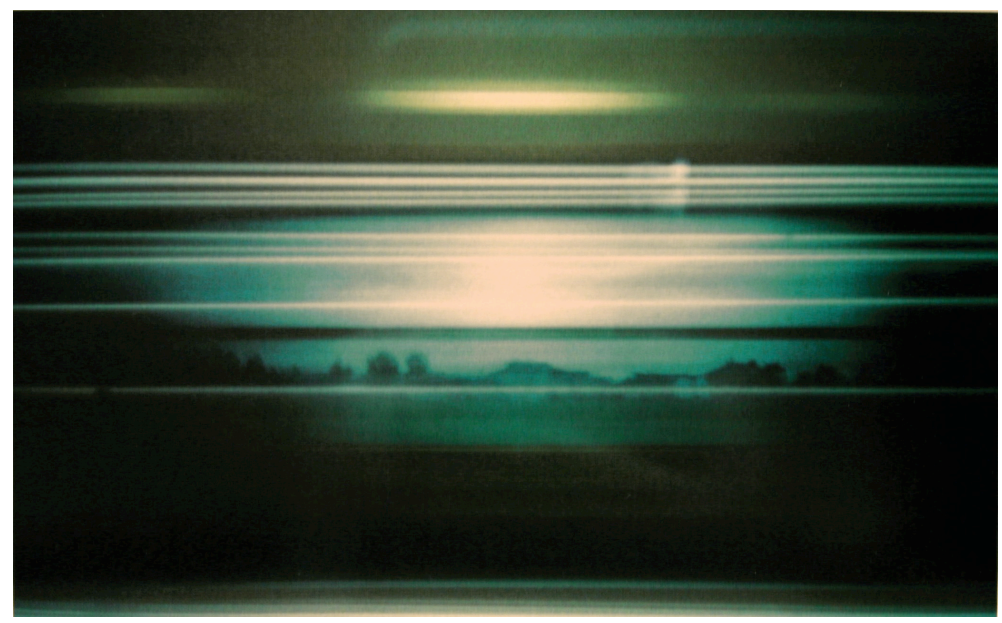

F4. Through the windows of two crossing trains, 1991, de Rivka Rinn

En la imagen Through the windows of two crossing trains, 1991 (F4) de la artista Rivka Rinn lo que vemos es el paisaje visto desde y a través del transporte. La imagen, tomada justo en el momento en el que se cruzan dos trenes (según su propio título), muestra a través de las ventanillas un horizonte 'natural' al fondo. Sin embargo éste ha sido recortado y mediatizado por la ventanilla a través de la que miramos y la del otro tren que coincide con ella (el segundo tren opera a modo de obturador de la ventanilla del tren en el que va la fotógrafa). Líneas y luces horizontales cruzan la imagen lado a lado generadas por la velocidad del medio de transporte y la lenta velocidad de obturación que no capta el paisaje sino el paso del mismo.

Mi obra fotográfica se basa en el concepto de que la velocidad es uno de los factores centrales que caracterizan nuestra época. Capto imágenes durante viajes a gran velocidad por autopistas, dentro de trenes y aviones. Los sorprendentes resultados son como reveladoras visiones que nuestros ojos no conocen, y nos hacen conscientes de "aquello que el ojo no sabe que ve". (...) dentro de esta velocidad del moverse y del ver (siempre a través del objetivo), cada visión se convierte en recuerdo en una fracción de segundo. Un recuerdo en tiempo real. Un viaje desde el Lugar al Recuerdo del lugar mismo (Rinn, 2005, p. 92).

La fotografía no refleja la visión que tenemos nosotros desde dentro del transporte sino que nos devuelve la sensación que su paso rápido nos deja. 
La imagen a través de las ventanillas del tren muestra lo que el recuerdo del viaje ha generado.

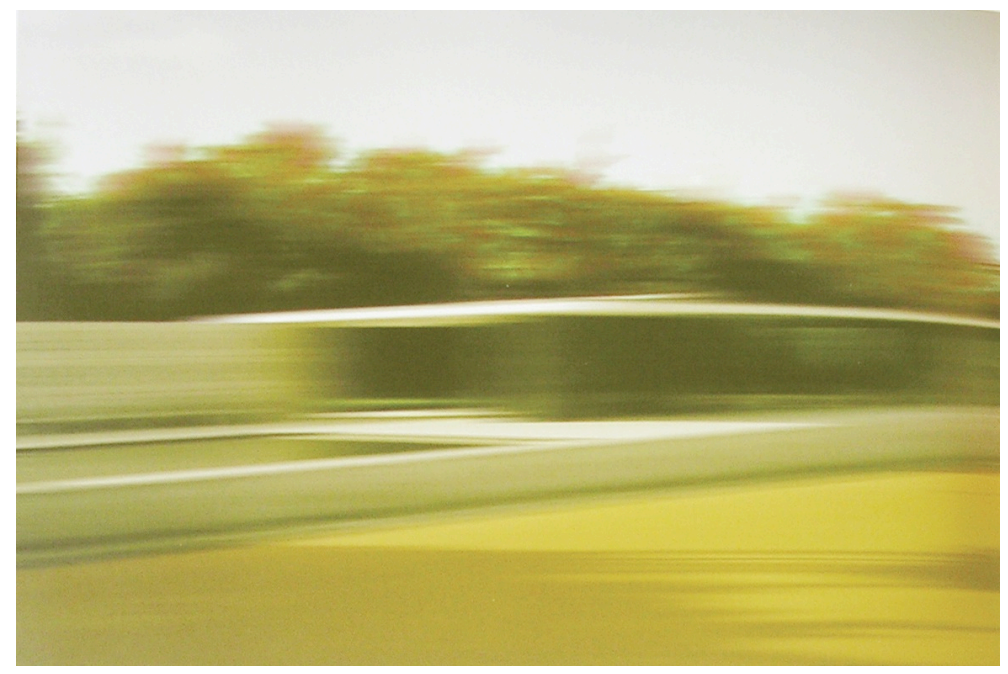

F5. d.p.b.o8, 2000, de la serie l.m.v.d.r. de Thomas Ruff

La fotografía d.p.b. o8, 2000 ( $\mathrm{F}_{5}$ ) de Thomas Ruff pertenece a su serie l.m.v.d.r., un encargo para fotografiar los edificios realizados por Mies van der Rohe (en este caso el pabellón de Alemania en la feria de Barcelona). En la imagen vemos uno de los edificios del arquitecto difuminado en la horizontal como si lo hubiéramos mirado a través de un vehiculo a gran velocidad, lo que ha provocado: la saturación de los colores, la pérdida de los contornos y la elevación del brillo.

Los títulos de las fotografías de la serie se corresponden a una especie de código de búsqueda informático, mezcla de las iniciales de los edificios y la modificación digital. El trabajo se basa en el estudio de la propia arquitectura y de las fotografías ya existentes de los edificios, utilizando estas con distintas transformaciones informáticas.

Las imágenes de esta serie de Thomas Ruff no son el resultado de la obturación sino del tratamiento digital para dar la sensación deseada sobre el entorno. El tratamiento digital de la imagen produce efectos pictóricos, aunque estas fotografías no responden a la captura 'pictoricistaperspectivista realista' sino a la recreación pictórica interiorizada de lo real. La imagen tratada digitalmente intenta conseguir, a partir de una misma 
imagen, una nueva sensación espacio temporal, la imagen de la velocidad o el paso rápido que produce ráfagas en la fotografía d.p.b. o8, 2000.

El ojo no ve lo que las fotografías nos enseñan, un viajero fijará su mirada en el horizonte para observar el paisaje, no en lo que está al lado del vehículo en movimiento que pasa demasiado deprisa. Sin embargo esa sensación de ráfaga ante nuestros ojos se corresponde con algo que hemos sentido a lo largo de nuestros viajes. Las fotografías intentan representar la sensación espacio-temporal en una imagen plana.

El barrido de la imagen sobre la realidad da sensación de velocidad. Cuando vamos en un medio de transporte, aunque no nos demos cuenta, el paisaje pasa ante nuestros ojos a distinta velocidad dependiendo de la distancia a la que se encuentre. Lo más cercano pasa muy rápido y lo más lejano, aquello que está en la línea del horizonte, pasa mucho más despacio. El paisaje desde el transporte es como una circunferencia que gira alrededor de nuestra ventanilla. Lo que está cerca pasa muy rápido desdibujándose en líneas horizontales que dejan una estela ante nuestra vista, por eso no vemos lo que está, sólo lo apreciamos.

Las dos fotografías que nos ocupan se fijan en la generación de ese rastro de las cosas al paso del transporte. Si ponemos nuestra atención en lo que está cerca sólo veremos su estela, un indicio de líneas horizontales.

Las líneas horizontales que dibujan las imágenes generan una similitud perceptiva con el viaje en sí. Las líneas horizontales generan contigüidad en el espacio del cuadro, continúan más allá de sus lados laterales, no se paran en el marco. Sabemos que nos movemos porque las líneas se alargan y tienden a pasar de adelante a atrás, de izquierda a derecha.

La velocidad trata la visión como materia prima, con la aceleración viajar equivale a filmar, no tanto producir imágenes cuanto huellas mnemónicas nuevas, inverosímiles, sobrenaturales (Virilio, 1988, p. 67). 


\subsection{Abstracciones}

La fotografía Time Square, 1998, de la serie My Own Rave (F1) combina en la imagen las características de los otros dos pares que hemos visto hasta ahora: la imagen múltiple y rápida, el universo desde cerca y desde lejos mezclado con las ráfagas que su visión en movimiento nos sugiere. El fotógrafo italiano Davide Bramante nos muestra la principal plaza de Manhattan, en la esquina entre las calles Broadway y Séptima Avenida de Nueva York. El entorno está lleno de luminosos, pantallas enormes y neones que la han convertido en icono de la ciudad, una norma de la zona obliga a sus moradores a colocar señales brillantes, pantallas..., compitiendo ya en densidad luminosa con las Vegas.

Davide Bramante realiza la imagen, o imágenes para su fotografía, por la noche para acentuar las características del entorno, los luminosos se ven en todo su esplendor y las luces de los coches al pasar dejan la estela de su movimiento. La noche hace más intensa la luz que llena la plaza. La imagen mezcla la visión múltiple y rápida: rojo, azul, blanco y amarillo brillante para romper el negro, logotipos, pantallas con anuncios, caras de mujeres y productos, faros, estelas y rastros del color de los coches... todo superpuesto en capas semitransparentes para dejarnos ver desde distintos puntos de vista al mismo tiempo. Parece que la imagen suena, el sonido monótono y saturado del tráfico que lo atraviesa (óiganse la grabación en directo de la plaza, earthcam.com), y aunque la imagen bidimensional no tiene sonido nos da sensación de ruido. Parece que la imagen adquiriera el movimiento que ha pretendido condensar a partir de la sensación que el propio entorno genera.

Hemos visto como tanto las imágenes que fusionan una visión múltiple, como las que se dibujan a partir de la ráfaga, están mediatizadas. Todas se generan por la interposición del dispositivo, no sólo fotográfico, ante la mirada. No se trata de la relación con el entorno inmediato a escala humana, sino de la relación del individuo contemporáneo con todo el entorno concebible o consciente que le permiten los transportes: aviones, coches, autobuses... En las fotografías a análisis no vemos lo que el 'ojo ve 
directamente' o lo que está acostumbrado a percibir, sino que observamos una recreación de lo que se siente.

Las imágenes están mediatizadas para representar una sensación. No hay que olvidar que la 'fotografía' figurativa y realista también construye una imagen mediatizada, la diferencia es que ésta ya ha sido aceptada y sin embargo: lo borroso, las mezclas de colores, texturas, fusiones, degradados, filtros, interposiciones... constituyen una forma que intenta enseñarnos cómo se puede comprender el entorno actual.

Abstracciones digitales, mezclas y saturaciones...para generar una imagen múltiple y rápida, un montaje que parece acumular el espacio-tiempo en una sola imagen bidimensional.

\subsection{Distancias}

\subsubsection{Cerca y lejos}

El ser humano actual comprende el entorno desde una posición distinta a la que se había mantenido desde el Renacimiento, sabe que el tiempo no es lineal, sino que está relacionado con el espacio, y además, que todo se mueve, él y todo lo que le rodea, aunque no sea consciente de ello.

Los recursos compositivos de las imágenes analizadas sirven para poner de relieve que las relaciones con la realidad son distintas a épocas pasadas. Si el ser humano del Renacimiento no podía ni imaginar la existencia de entornos tan extensos era porque su composición del mundo se ajustaba a partir de la relación directa con su cuerpo. En la actualidad se puede tener consciencia de un mundo global, de un entorno tan extenso como por ejemplo la ciudad de México y de la posición dentro de esa gran ciudad.

Para llegar a comprender el entorno contemporáneo tendremos que fijarnos en dos características que definen lo urbano y que están reflejadas respectivamente en los dos pares de imágenes a análisis. El entorno contemporáneo es uniforme y homogéneo, como muestran las fotografías de México de la serie Netropolis (F2) de Michael Najjar o la de Xiang Liqing de 
la serie Rock Never de 2002 (F3). La visión desde lejos reproduce a lo largo de todo el mundo una imagen repetitiva y similar.

La creación de tales redes entre las metrópolis que se está llevando a cabo genera una marcada homogeneización entre las ciudades. Ya sea en Nueva York o Tokio, Sao Paulo o Shangai, se encuentran las mismas imágenes, los productos básicos, las máquinas, los medios de comunicación y tecnologías de conocimientos científicos. David Harvey proclamaba en La condición de la postmodernidad, que el rápido viaje a través de la ciudad así como a través del espacio ultraterrestre es el modelo de la implosión del espacio y tiempo que las comunicaciones globales generan (Najjar, 2004).

Esta homogeneización del entorno deviene de la expansión mundial de los medios de transporte que han variado ya para siempre nuestra relación con el entorno espacio-temporal. La imagen que veamos a través de ellos estará compuesta por líneas de un entorno desdibujado y difuso, como en la imagen Through the windows of two crossing trains (F4) de la artista Rivka Rinn o d.p.b. $08\left(\mathrm{~F}_{5}\right)$ de Thomas Ruff.

Si vamos rápido o estamos lejos lo que veremos tendrá una composición abstracta y compleja, repetitiva y sistemática. Las fotografías a análisis nos muestran una visión lejana en la que se superponen visiones que reproducen un entorno homogéneo que no se puede entender en su complejidad; y/o una visión cercana desde el medio de transporte que hace que todo lo que está cerca se desdibuje y casi borre ante nuestros ojos.

\subsubsection{Borroso}

Borroso, complejo, imbricado... es difícil representar algo que se siente, que se intuye pero que no se ve... en una imagen plana, bidimensional y aparentemente figurativa. El montaje que hace repetir la imagen en las dos primeras fotografías y la captura del movimiento a través del transporte en las dos siguientes, son formas de composición o captura-representación de la realidad que responden a la necesidad de plasmar la acumulación espaciotemporal que se produce al interiorizar el entorno urbano. 
Estas formas de composición y representación (el collage o la larga exposición) se han utilizado a lo largo de la historia del arte, pero sólo para intentar acumular en la imagen plana bidimensional la cadencia del paso del tiempo, el tiempo lineal, como explica Aumont.

El collage temporal sería, pues, el modo más frecuente de representación del tiempo en la pintura, incluso cuando ésta tuvo la pretensión de representar un instante único, ya que como hemos visto, el instante esencial es casi siempre equivalente a un pequeño montaje. Pero se puede llegar aún más lejos y preguntarse si la fotografía misma, cuando el tiempo de exposición excede al de la más breve instantánea, no funciona del mismo modo. La acción de la luz sobre la superficie fotosensible se produce durante todo el tiempo de apertura del obturador, cualquiera que ésta sea: apenas es algo larga (pongamos, a partir de una décima de segundo), la foto fija la huella de pequeñas modificaciones temporales, en especial pequeños movimientos (pero no solamente eso: es, por ejemplo, la luz la que ha podido cambiar), de manera continua. Esta huella no aparecerá, tal como los collages o montajes de los que hablábamos antes, puesto que es de un solo acto, de una sola pieza. No por eso deja de ser cierto que la imagen, de algún modo, habrá acumulado tiempo, desplegándolo espacialmente. Esa podría ser pues la fórmula más general de la síntesis temporal en la imagen: a puntos diferentes en el espacio de la imagen corresponden puntos diferentes en el tiempo del suceso representado (Aumont, 1992 p. 251).

Si Aumont cree que ambas formas de generar imagen producen una acumulación de tiempo para desplegarlo en el espacio sólo es porque no se ha dado cuenta de que estas formas de representación a lo largo del siglo XX no acumulaban sólo tiempo, sino que acumulaban invariablemente espacio, ambos están tan conectados que no se pueden separar.

Las imágenes no plasman la acumulación del tiempo, sino la acumulación del espacio-tiempo. Ya sea en la misma toma, la ventanilla del tren, o posteriormente en los collages y montajes. Las fotografías intentan representar en 2D un entorno espacio-temporal cuatridimensional, en el que el espacio y el tiempo no se pueden separar. 
Desde el Renacimiento se cree que el tiempo es algo lineal, y cuando llegó la fotografía parecía incluso que ésta era capaz de alargar cualquier momento en un tiempo congelado, de arrancarle un instante. Las imágenes a estudio en este apartado muestran la acumulación del espacio-tiempo por la cantidad y densidad de información que es capaz de transmitir el entorno urbano.

Ahora somos conscientes de que nuestro punto de vista cambia con respecto a lo que tenemos delante porque tanto el entorno como nosotros mismos estamos en un movimiento continuo. Esto hace muy complejo aplicar una posición única para poder observar lo que nos rodea. Todo cambia y se transforma, nosotros también, ¿dónde podemos poner la atención dentro de esa imagen borrosa?, ¿qué ha cambiado de nuestro concepto del mundo?

\subsubsection{Densidad}

Las fotografías funcionan como un caleidoscopio de la realidad urbana. Un caleidoscopio porque mueven y mezclan las realidades que la componen en una sola imagen plana, pero además porque intentan poner de manifiesto las posiciones posibles del espectador con respecto a esta nueva realidad.

La realidad urbana es la encarnación material de la densidad de información. Como Florian Rötzer observó, "las ciudades son estructuras de densidad espacial, lo que representa el nexo de la territorialidad basada en el orden social jerárquico, con el objetivo de lograr la más rápida interacción entre sistemas de gran complejidad" (...) Ahora nuestro camino se ha denominado "sociedad telemática" - una sociedad en la que, según el filósofo de los medios de comunicación Vilem Flusser, el individuo se mueve cada vez más en un universo de imágenes técnicas, donde las estructuras sociales están orientadas a la producción de información y su distribución a través de las redes (Najjar, 2004).

Xiang Liqing, retrata en el montaje de su serie Rock Never de 2002 (F3) la ciudad global densa, Hangzhou y Shangai, China (en el delta de río de la Perla), de donde salen los buques portacontenedores repletos de productos 
chinos para el resto del mundo, y donde se está produciendo la mayor concentración urbana de la historia.

La densidad de información, la densidad de intercambio de materiales, la imbricada red de distribución de unos y de otros, la interacción de todos los complejos procesos... produce densidad en sus imágenes.

Pero esa trama está sustentada en especial por la red de transportes que ha generado una nueva relación espacio-temporal con el entorno que nos rodea. Tardamos mucho menos tiempo en recorrer los espacios entre los puntos privilegiados de la red y esto produce la aceleración de la mirada sobre el entorno que dejamos atrás de nuestra ventanilla en el transporte. Las fotografías Through the windows of two crossing trains (F4) de la artista Rivka Rinn y d.p.b. 08 ( $\mathrm{F}_{5}$ ) de Thomas Ruff, nos muestran la ráfaga que se produce en el entorno a nuestro paso.

Si ese es el entorno por el que nos movemos, las sensaciones que se generen serán: múltiples, saturadas, rápidas; es decir, densas.

\section{Conclusiones}

Cada individuo tiene una medida personal del tiempo, por lo tanto también del espacio, medida que depende de dónde está y cómo se mueve (Hawking, 1990, p. 62). Esto implica una estructura del entorno y unos movimientos en él que tienen consecuencias en nuestra vida diaria.

Davide Bramante en su obra Time Square 1998 de la serie My Own Rave propone una visión simultánea, múltiple y rápida, para recrear el frenesí del momento actual. Como en tantos retratos dedicados a las más diversas ciudades del mundo que ha mostrado en sus fotografías, Bramante también abarca toda una sociedad, con todos sus aspectos visibles en el mismo tiempo. Como dice el artista: Para mí, estas fotos son la imagen exacta de la sociedad contemporánea (Bramante, Studio La Città). En My Own Rave: mi propio testimonio, delirio, alarde... expone su visión y la visión personalizada que cada uno podría tener. 
Las imágenes intentan explicar que cada uno de nosotros tenemos que ser conscientes de nuestra posición, movimiento y punto de vista, aquel que genera una visión determinada sobre el entorno, en las que se mezclan las posibilidades del entorno con las nuestras. Los fotógrafos han conseguido plasmar las características y las sensaciones del entorno frenético que compartimos en la actualidad, aunque aparentemente éste no se pueda registrar directamente en una sola imagen bidimensional.

Según Paul Virilio, el avance de los medios de transporte y las construcciones necesarias para su mantenimiento ha crecido en progresión geométrica (Virilio, 1997). La gran revolución del vapor y el carbón de la modernidad no sólo se ha consolidado con la revolución del petróleo y la chispa eléctrica, sino que (y la idea es suya), ha generado la aceleración del entorno. Los desarrollos de las ciudades y del urbanismo tienen que ver con las tecnologías del transporte o de transmisión y siempre ha sido así. Pero, en la actualidad la aceleración de estos avances es de tal calibre que el sujeto ha abandonado la escala humana por otra basada en la velocidad. Hasta ahora la dimensión del entorno con el que se relacionaba el sujeto estaba basada en el cuerpo humano, la transformación que supone la aceleración de los medios de transporte provoca una contaminación de las distancias tangibles.

Apreciar el entorno desde los medios supone entenderlo desde una nueva escala, una nueva relación que se manifiesta en una estructura de red.

Cuando observo, por ejemplo, una vista aérea de Île-de-France, contemplo una aglomeración desconocida en la que nunca he puesto ni los ojos ni los pies, e incluso si el mapa de París no es el territorio urbano, esa cartografía me resulta infinitamente más preciosa que su visión atmosférica, puesto que me indica las rupturas, los quiebres de simetría, en una palabra, la fractalización de un tejido que la fotografía no permite adivinar nunca (Virilio, 2006, p. 14).

La fotografía artística actual, como hemos visto en los análisis, ha conseguido plasmar esa nueva relación y esa nueva estructura, esa estructura fractal, esa red que deviene de la nueva reacción con un entorno como escala. Por supuesto, no es la fotografía que estábamos acostumbrados a ver, no, es la 
que surge de esta nueva relación. Los fotógrafos artistas representan las nuevas sensaciones que esta relación genera por medio de registros que se alejan de los cánones ortodoxos de la figuración fotográfica.

La fotografía artística contemporánea propone nuevas formas simbólicofigurativas, figurativas porque la mayoría de ellas siguen siendo tomas directas y posibles, desde el sentido de la visión-cámara (o que intentan imitar a éstas), de representación de la realidad: juego de niños, cambio de perspectivas, visión múltiple y compleja, maquetas, abstracciones, etc.

Un ejemplo de lo que estamos diciendo es el trabajo del fotógrafo Adam Magyar, que ha desarrollado una cámara que le permite tomar una imagen continua a través de una ranura, es decir, la cámara recoge puntos consecutivos en el tiempo horizontal, una línea vertical tras otra de la información que se coloca delante de ella (ver vídeo explicativo en su página web).

Los intervalos de tiempo y espacio registrados de esta manera se colocan uno al lado del otro generando una imagen sin punto de vista, es el paso del tiempo mismo lo que se convierte en el espacio por avanzar en el tiempo desde el lado derecho hasta el izquierdo en cada imagen. (...) Como resultado de esta conexión espacio-tiempo, todas las personas y vehículos en las fotos van en una dirección (Magyar, 2008).

La imagen resultante es una imagen plana que ha condensado un aspecto de la realidad circundante de una manera nueva, nueva en cuanto a que no responde a los cánones ortodoxos de representación de la realidad. La técnica dibuja figuras de los cuerpos y objetos que se mueven por delante de ella, y sin embargo traza líneas rectas continuas de píxeles iguales, como si fueran estelas, de las cosas que están quietas. Parece que esta fotografía es capaz de captar el movimiento continuo de todo cuerpo en reposo.

La fotografía contemporánea utiliza los recursos técnicos, formales o la mezcla de ellos según le convenga para la obtención de la imagen deseada: desde la estela del movimiento provocada por el transporte, a la generada informativamente; de la superposición contigua, al montaje; de la visión 
aérea, a la ocupación a intervalos regulares que configura un mundo de juguete...

Esa es la función de la fotografía artística contemporánea, descubrir la estructura a través de la cual se construye el entorno, el mundo, y la idea del mismo. El resultado nos revela una nueva estructura del entorno. Desde el renacimiento el ser humano sólo se puede situar en el suelo mirando el mundo desde el único ojo que le otorgaba la perspectiva cónica, pero el ser humano de finales del XX y principios del XXI puede, además de seguir utilizando su ojo cónico concebir otra nueva forma de relacionarse con lo que le rodea. La estructura contemporánea propone una disposición de trama o malla con fluido intercambio entre sus nodos (a escala de lo macro a lo micro y de lo micro a lo macro) para comprender el entorno en la actualidad. Las fotografías nos lo demuestran enseñándonos: lo borroso, lo imbricado, lo complejo, lo caótico, lo múltiple, lo fugaz, lo micro y lo macro, lo regular, lo reticulado... lo abstracto.

\section{Referencias bibliográficas}

Aumont, J. (1992). La imagen. Barcelona: Paidós.

Bramante, D. www.davidebramante.it (consulta 13-03-2011). http://www.davidebramante.com/db/home.html (21-10-2015)

Calvo Serraller, F. (2005) Los generos de la pintura. Madrid: Taurus.

Chevrier, J-F. (2007). La fotografía entre las bellas artes y los medios de comunicación. Barcelona: Gustavo Gili.

Debray, R. (1994), Vida y muerte de la imagen en occidente. Historia de la mirada en occidente. Madrid: Paidos.

Gombrich, E.H. (2002). Arte e ilusión: estudio sobre la psicología de la represenación pictórica. Madrid: Debate.

Hawking, S. (1990). Historia del tiempo. Del big bang a los agujeros negros. Barcelona: Alianza.

Hawking, S. (2000). El universo en una cáscara de nuez. Barcelona: Círculo de Lectores.

Kessler, M. (200o). El paisaje y su sombra. Barcelona: Idea Books.

Kuhn, T., (1962) La estructura de las revoluciones científicas. University of Chicago Press. 
Ledo, M. (1998). Documentalismo fotográfico. Madrid: Cátedra.

Lowe, D. M. (1986) Historia de la percepción burguesa. México DF: Fondo de Cultura Económica.

Maderuelo, J. (1997) "Paisajes descritos: un paseo por la literatura" en Actas. El paisaje. Arte y Naturaleza, 1996. Huesca: Diputación de Huesca.

Magyar, A. (2008) "Urban flow" project info, text. [vídeo explicativo de la técnica de captación inventada por él] www.magyaradam.com (consulta 1507-2015).

Martín, Alberto. “Comunidades y lugares”. El País, 16 de junio de 2007. Recuperado elpais.com/diario/2007/o6/16/babelia/1181948773_850215.html (consulta 12-10-2015).

Najjar, Michael. www.michaelnajjar.com/ (consulta 6-08-2015).

Rinn, R. www.rivkarinn.org (consulta 26-9-2015).

Ruff, T. Recuperado de www.fundaciontelefonica.com/arte_cultura/patrimonio/ (consulta 1510-2015).

Spalding, D. (2003) "Xiang Liqing: An Architecture of Resistance". Recuperado de www.shanghartgallery.com/galleryarchive/texts/id/195 (consulta 1306-2015).

Vega, P (2007). “Tiempo y movilidad en el territorio suburbial”. Jornadas sobre capital y territorio I 2007. Universidad Internacional de Andalucía (de la naturaleza del espacio... y del arte. Recuperado deayp.unia.es/index.php?option=com_content\&task=view\&id=126 (consulta 22-03-2011).

Virilio, P. (1988). Estética de la desaparición. Barcelona: Anagrama.

Virilio, P. (1997). "La pérdida del mundo o cómo reencontrar el cuerpo propio". El cibermundo, la política de lo peor. Madrid: Cátedra.

Virilio, P. (2006). Ciudad pánico, el afuera comienza aquí. Buenos Aires: Libros del Zorzal.

Cómo citar: Pastor Andrés, G. (2016). "Frenético, el espacio-tiempo en la fotografía artística contemporánea”. Fotocinema. Revista científica de cine y fotografia, $\quad \mathrm{n}^{\mathrm{O}} \quad 12, \quad \mathrm{pp} . \quad 103^{-129} \quad$ Disponible: http://www.revistafotocinema.com/ 